\title{
Glucocorticoids Improves Pregnancy Rate and Outcome in Woman With Unexplained Positive Autoantibody: a Systematic Review and Meta- analysis
}

\section{Ting Li}

Peking University Third Hospital https://orcid.org/0000-0002-2950-614X

Yilin Yuan

Peking University Sixth Hospital

Huixin Liu

Peking University People's Hospital

Qun Lu

Peking University People's Hospital

Rong Mu ( $\square$ murong@pkuph.edu.cn )

Department of Rheumatology and Immunology, Peking University Third Hospital

\section{Research article}

Keywords: GCs, unexplained positive autoantibody, pregnancy outcome, meta-analysis

Posted Date: January 19th, 2021

DOI: https://doi.org/10.21203/rs.3.rs-147807/v1

License: (c) (1) This work is licensed under a Creative Commons Attribution 4.0 International License. Read Full License 


\section{Abstract}

Background: The effect of glucocorticoids (GCs) therapy for women with unexplained positive autoantibody is under debate. This systematic review and meta-analysis was performed to evaluate whether GCs administration can improve the pregnancy outcome of this population.

Methods: A meta-analysis based on a systematic review of PubMed, Embase, EBSCO, and the Cochrane Central Register of Controlled Trials, until January 2021, was used to evaluate pregnancy outcome of GCs treatment for women with unexplained recurrent fetal loss or infertility whose autoantibody positive, but does not meet any classification criteria for autoimmune diseases.

Results: We found GCs treatment improved clinical pregnancy rate (RR 2.19, 95\% $\mathrm{Cl} 1.64$ to 2.92 ) and live birth rate (RR $1.92,95 \% \mathrm{Cl} 1.17$ to 3.16), especially when started GCs administration before pregnancy (clinical pregnancy rate: $\mathrm{RR} 2.30,95 \% \mathrm{Cl} 1.58$ to 3.34 ; live birth rate: $\mathrm{RR} 2.30,95 \% \mathrm{Cl} 1.58$ to 3.34 ). However, no effect of GCs on miscarriage rate was found (RR $0.75,95 \% \mathrm{Cl} 0.55$ to 1.02 ) regardless of time of drug administration.

Conclusions: Our systematic review and meta-analysis surports the rational use of GCs in women with unexplained positive autoantibody.

\section{Introduction}

Human fertility is declining globally. The global infertility rate is about $14 \%$ and miscarrage rate is up to $10 \%-15 \%[1,2]$. Infertility or miscarriage, in broad sense, is the result of failed establishment or maintenance of pregnancy. Although advancement have been achieved in technology, such as in vitro fertilization-embryo transfer (IVF-ET), nearly half patients undergoing IVF-ET can not gain a successful pregnancy ${ }^{[3]}$ which is frustrating experience for both patients and clinicians. To improve pregnancy outcome is of great importance. Maternal immune tolerance to the placenta and the fetus is one of the key factors in establishing and maintaining pregnancy. Immunological abnormality was reported to account for $27.88 \%$ of fetal loss, include overproduction of autoantibodies and proinflammatory cytokines, and imbalance of immune cells ect ${ }^{[4,5]}$.Women with autoantibody-positive can be divided into two groups based on whether they are diagnosed with autoimmune diseases. The chance of a live birth was significantly reduced in women with rheumatoid arthritis receiving ART treatment, relative to women without rheumatoid arthritis ${ }^{[6]}$. Antiphospholipid syndrome accounts for $\sim 3.2 \%$ recurrent pregnancy loss in the first trimester ${ }^{[7]}$. However, those diseases only account for a small proportion of all immune factors affecting obstetrics. When it comes to more often cases, autoantibody positive women with recurrent fetal loss or a history of recurrent implantation failure who cannot be classified into any known autoimmune disease, guidelines are insufficient. It remains marginalized in terms of improving pregnancy outcome of this population. 
For infertile women with unexplained positive autoantibody, empirical treatment takes a mainstay possession. Several therapies have been proposed in daily practice ${ }^{[8]}$, among which glucocorticoids (GCs) are a group of classic drugs for autoimmune diseases. However, the effect of GCs in improving pregnancy outcome in women with unexplained positive autoantibody is controversial. Furthermore, dispute of GCs treatment remains in matters of drug selection, initial treatment time, dosage of GCs, and period of treatment. It's demanding to determine whether GCs treatment is beneficial to pregnancy outcome in women with unexplained positive autoantibody, as the treatment regimen is quite arbitrary and confusing in daily practice. Therefore, we reviewed clinical research content, and did systematic review and meta-analysis around treatment effect of GCs on this populationsystematic review, in hoping to provide evidence for rational drug use in women with unexplained positive autoantibody.

\section{Methods}

\section{Search strategy and selection criteria}

This study has been registered with PROSPERO (the registration number: CRD42019124442), and was conducted and reported according to the Preferred Reporting Items for Systematic Review and Metaanalysis (PRISMA) statement ${ }^{[9]}$. We conducted a systematic search both in English and Chinese in Pubmed, Embase, EBSCO, and the Cochrane Central Register of Controlled Trials. For comprehensive literature search, a string made up of relevant keywords was utilized: ("glucocorticoids" or "steroid" or "prednisone" or "prednisolone" or "methylprednisolone" or "dexamethasone") and ("recurrent fetal loss" or "recurrent pregnancy loss" or "recurrent spontaneous miscarriage" or "infertility" or "assisted reproductive technique" or "IVF-ET" or "recurrent implantation failure") and ("autoimmune" or "autoantibody"). The time of publication was not limited.

Two independent reviewers (Yilin Yuan and Ting Li) reviewed titles and abstracts for basic relevance, followed by a full-text examination using the following inclusion and exclusion criteria. Only Randomized controlled trials (RCT) and cohort study investigating the use of GCs in women with unexplained positive autoantibody undergoing pregnancy were assessed based on full text. Any discordant findings between the two independent reviewers were adjudicated by a third reviewer.

The inclusion criteria are as follows: unexplained recurrent fetal loss or infertility; with autoantibody positive, but does not meet any classification criteria for autoimmune diseases; intervention group treated with GCs and control group given placebo or untreated.

The exclusion criteria includes repeated data, being diagnosed with specific autoimmune disease, lack of positive autoantibodies, lack of GCs administration, and risk of confounding factors such as thyroid function anomaly.

\section{Quality assessment}


RCTs were quality assessed based on the criteria outlined in the Cochrane Handbook for Systematic Reviews of Interventions (Higgins 2011). Retrospective cohort studies were quality assessed based on the New Castle-Ottawa Quality Assessment Scale-Cohort Studies. Two authors independently assessed every paper.

\section{Data extraction and analysis}

The following data were extracted: the number of enrolled patients, status of autoantibodies, the type of GCs, initial GCs treatment time, dosage of GCs, period of treatment, combination therapy, the number of clinical pregnancy, live birth, and miscarriage (per pregnancy).

The primary outcome in our study is relative risk (RR) of establishment of clinical pregnancy comparing GCs-treatment and non-GCs-treatment group.

The secondary outcomes in our study are: 1) RR of live birth rate (per couple) comparing GCs-treatment and non-GCs-treatment group; 2) RR of miscarriage rate (per pregnancy) comparing GCs-treatment and non-GCs-treatment group.

We examined the heterogeneity (variations) between the results of different studies by checking the results of the chi-squared Cochran's $Q$ statistic and $I^{2}$ statistics. $I^{2}>50 \%$ represent statistical significance for heterogeneity, random-effects models were used if heterogeneity presents. All analysis were conducted by Cochrane Collaboration' Review Manger 5.3 software package.

\section{Results}

Using the keywords and database listed above, 7 studies were identified for inclusion. During the initial search, we identified a total of 114 studies by searching strategy in all four databases. After eliminating 57 duplicate records and 29 studies not relevant to our research question, 28 studies remained suitable for following screening. Among these, we excluded 21 studies $^{[10-30]}$ (see supplementary table 1 for studies excluded and reason for exclusion). 7 studies meet the inclusion criteria with no reason for exclusion, providing data comparing peri-implantation GCs versus placebo (or untreated). Full agreement existed between the two review authors concerning inclusion or exclusion trials.

Among the 7 studies identified, 5 studies were parallel-design RCT, 2 studies were cohort studies. All were single center studies. The risk of bias is listed in supplementary table 2 and 3.

\section{Participants}

681 participants were included from 7 independent studies. Among these studies, one study further divided their participants into subgroups with positive ANA or APL [31] (Table 1). 3 studies included women who are positive for one of the autoantibodies, including antinuclear antibody (ANA), anti-DNA (anti-dsDNA by Geva et al., anti-ssDNA and anti-dsDNA by Ando et al. and Laskin et al.), anticardiolipin antibody (ACL), lupus anticoagulant (LAC), antilymphocyte antibody ${ }^{[31-33]}, 2$ studies included only 
women with positive ANA ${ }^{[34,35]}$, one study included only women with positive antiphospholipid antibody (APL). ${ }^{[36]}$ One study included women whom had thyroid peroxidase antibodies (TPO-Abs) with normal thyroid function ${ }^{[37]}$. 
Table 1

Characteristics of participants of included studies.

\begin{tabular}{|c|c|c|c|c|c|}
\hline Study & Age & $\begin{array}{l}\text { Indication } \\
\text { for } \\
\text { treatment }\end{array}$ & $\begin{array}{l}\text { Autoantibody } \\
\text { profile }\end{array}$ & GCs use & $\begin{array}{l}\text { Adjuvant } \\
\text { therapy }\end{array}$ \\
\hline \multirow{4}{*}{$\begin{array}{l}\text { Fan, } \\
2016^{[35]}\end{array}$} & \multirow{4}{*}{$\begin{array}{l}31.1 \\
\pm 4.2\end{array}$} & \multirow{4}{*}{$\begin{array}{l}\text { IVF-ET } \\
\text { failure }\end{array}$} & \multirow[t]{4}{*}{ Positive for ANA } & Prednisone: 10 mg/d & \multirow{4}{*}{$\begin{array}{l}\text { Aspirin: } \\
100 \mathrm{mg} / \mathrm{d} \\
\\
\text { Administered } \\
\text { simultaneously } \\
\text { with GCs }\end{array}$} \\
\hline & & & & Started 3 months before & \\
\hline & & & & $\mathrm{COH}$ & \\
\hline & & & & $\begin{array}{l}\text { Stopped if confirmation of } \\
\text { clinical pregnancy }\end{array}$ & \\
\hline \multirow[t]{3}{*}{$\begin{array}{l}\text { Turi, } \\
2010^{[37]}\end{array}$} & \multirow[t]{3}{*}{$\begin{array}{l}34.4 \\
\pm 3.8\end{array}$} & \multirow[t]{3}{*}{ Infertilty } & \multirow[t]{3}{*}{$\begin{array}{l}\text { Positive for } \\
\text { antithyroid } \\
\text { antibody }\end{array}$} & $\begin{array}{l}\text { Prednisone: } 10 \mathrm{mg} / \mathrm{d}^{*} 1 \\
\text { week, } 5 \mathrm{mg} / \mathrm{d}^{*} 1 \text { week, } \\
2.5 \mathrm{mg} / \mathrm{d}^{* 1} \text { week, and } \\
2.5 \mathrm{mg} / \mathrm{d} * 3 \text { times }\end{array}$ & \\
\hline & & & & Started 4 weeks before IUI & \\
\hline & & & & Stopped just before IUI & \\
\hline \multirow[t]{4}{*}{$\begin{array}{l}\text { Geva, } \\
1998^{[32]}\end{array}$} & \multirow[t]{4}{*}{ n.d. } & \multirow[t]{4}{*}{$\begin{array}{l}\text { IVF-ET } \\
\text { failure }\end{array}$} & \multirow{4}{*}{$\begin{array}{l}\text { Positive for } \\
\text { ANA, anti-ds } \\
\text { DNA, ACL or } \\
\text { LAC }\end{array}$} & \multirow{4}{*}{$\begin{array}{l}\text { Prednisone: } 10 \mathrm{mg} / \mathrm{d} \\
\text { Started } 4 \text { weeks before } \\
\text { induction of ovulation } \\
\text { Stopped at } 18 \text { th week of } \\
\text { gestation, IVF-ET failure or } \\
\text { fetal loss }\end{array}$} & $\begin{array}{l}\text { Aspirin: } \\
100 \mathrm{mg} / \mathrm{d}\end{array}$ \\
\hline & & & & & Started \\
\hline & & & & & with GCs \\
\hline & & & & & $\begin{array}{l}\text { Stopped } 6 \\
\text { weeks' } \\
\text { postpartum, IVF- } \\
\text { ET failure or } \\
\text { fetal loss }\end{array}$ \\
\hline \multirow[t]{4}{*}{$\begin{array}{l}\text { Laskin, } \\
1997^{[33]}\end{array}$} & \multirow[t]{4}{*}{$\begin{array}{l}3 \pm \\
3.8\end{array}$} & \multirow[t]{4}{*}{ RPL } & \multirow{4}{*}{$\begin{array}{l}\text { Positive for } \\
\text { ANA, anti-ds } \\
\text { DNA, ACL, LAC } \\
\text { or anti- } \\
\text { lymphocyte }\end{array}$} & \multirow{3}{*}{$\begin{array}{l}\text { Prednisone: } 0.8 \mathrm{mg} / \mathrm{kg} / \mathrm{d}^{*} \\
4 \text { weeks (maximum, } \\
60 \mathrm{mg}), 0.5 \mathrm{mg} / \mathrm{kg} / \mathrm{d} \\
\text { (maximum, } 40 \mathrm{mg} \text { ) } \\
\text { Started since confirmation } \\
\text { of pregnancy }\end{array}$} & $\begin{array}{l}\text { Aspirin: } \\
100 \mathrm{mg} / \mathrm{d}\end{array}$ \\
\hline & & & & & $\begin{array}{l}\text { Started } \\
\text { simultaneously }\end{array}$ \\
\hline & & & & & with GCs \\
\hline & & & & $\begin{array}{l}\text { Stopped at delivery or } \\
\text { fetal loss }\end{array}$ & $\begin{array}{l}\text { Stopped at 36th } \\
\text { week of } \\
\text { gestation or } \\
\text { shortly before } \\
\text { delivery }\end{array}$ \\
\hline \multicolumn{6}{|c|}{$\begin{array}{l}\text { Abbreviations: } \mathrm{RPL}=\text { recurrent pregnancy loss, } \mathrm{ANA}=\text { antinuclear antibody, } \mathrm{ACL}=\text { anticardiolipin } \\
\text { antibody, } \mathrm{LAC}=\text { lupus anticoagulant, } \mathrm{APL}=\text { antiphospholipid antibody, } \mathrm{COH}=\text { controlled ovarian } \\
\text { hyperstimulation, IUI = intrauterine insemination, IVF-ET = in vitro fertilization-embryo transplantation, } \\
\text { ICSI = intracytoplasmic sperm injection, n.d. = not defined. }\end{array}$} \\
\hline \multicolumn{6}{|c|}{ tFurther divided into subgroups according to autoantibodies, including $\mathrm{ANA}(+)$ and $\mathrm{LAC}(+)$} \\
\hline \multicolumn{6}{|c|}{$\begin{array}{l}\text { fFurther divided into } 2 \text { subgroups according to autoantibodies, including ANA(+)/APL(-) and } \\
\text { ANA(+)/APL(-) }\end{array}$} \\
\hline
\end{tabular}




\begin{tabular}{|c|c|c|c|c|c|}
\hline Study & Age & $\begin{array}{l}\text { Indication } \\
\text { for } \\
\text { treatment }\end{array}$ & $\begin{array}{l}\text { Autoantibody } \\
\text { profile }\end{array}$ & GCs use & $\begin{array}{l}\text { Adjuvant } \\
\text { therapy }\end{array}$ \\
\hline \multirow{4}{*}{$\begin{array}{l}\text { Ando, } \\
1996^{+[31]}\end{array}$} & \multirow{4}{*}{$\begin{array}{l}32.8 \\
\pm 3.4\end{array}$} & \multirow[t]{4}{*}{ n.d. } & \multirow{4}{*}{$\begin{array}{l}\text { Positive for } \\
\text { ANA, anti-DNA } \\
\text { or LAC }\end{array}$} & Prednisolone $5 \mathrm{mg} / \mathrm{d}$ & Aspirin: $81 \mathrm{mg} / \mathrm{d}$ \\
\hline & & & & $\begin{array}{l}\text { Or dexamethasone } \\
0.5 \mathrm{mg} / \text { day, changed into } \\
\text { prednisolone after } \\
\text { confirmation of pregnancy }\end{array}$ & \multirow[t]{3}{*}{$\begin{array}{l}\text { Administered } \\
\text { simultaneously } \\
\text { with GCs }\end{array}$} \\
\hline & & & & Started with IVF cycle & \\
\hline & & & & $\begin{array}{l}\text { Stopped according to } \\
\text { autoantibody titers }\end{array}$ & \\
\hline \multirow[t]{2}{*}{$\begin{array}{l}\text { Zhu, } \\
2013^{[34]}\end{array}$} & \multirow[t]{2}{*}{$\begin{array}{l}32.33 \\
\pm 4.25\end{array}$} & \multirow[t]{2}{*}{ Infertility } & \multirow[t]{2}{*}{ Positive for ANA } & Prednisone: $10 \mathrm{mg} / \mathrm{d}$ & $\begin{array}{l}\text { Aspirin: } \\
100 \mathrm{mg} / \mathrm{d}\end{array}$ \\
\hline & & & & $\begin{array}{l}\text { Up to } 3 \text { months before } \\
\text { IVF/ICSI cycle }\end{array}$ & $\begin{array}{l}\text { Administered } \\
\text { simultaneously } \\
\text { with GCs }\end{array}$ \\
\hline \multirow{2}{*}{$\begin{array}{l}\text { Ying, } \\
\text { 2012 }\end{array}$} & \multirow[t]{2}{*}{$\begin{array}{l}32.1 \\
\pm 4.0\end{array}$} & \multirow[t]{2}{*}{ Infertility } & \multirow[t]{2}{*}{ Positive for ACL } & $\begin{array}{l}\text { Methylprednisolone: } \\
8 \mathrm{mg} / \mathrm{d}\end{array}$ & \multirow{2}{*}{$\begin{array}{l}\text { Aspirin: } 50 \mathrm{mg} / \mathrm{d} \\
\text { Administered } \\
\text { simultaneously } \\
\text { with GCs }\end{array}$} \\
\hline & & & & $\begin{array}{l}\text { Up to } 3 \text { months before IVF } \\
\text { cycle }\end{array}$ & \\
\hline \multicolumn{6}{|c|}{$\begin{array}{l}\text { Abbreviations: RPL = recurrent pregnancy loss, ANA = antinuclear antibody, } A C L=\text { anticardiolipin } \\
\text { antibody, LAC = lupus anticoagulant, APL = antiphospholipid antibody, COH = controlled ovarian } \\
\text { hyperstimulation, IUI = intrauterine insemination, IVF-ET = in vitro fertilization-embryo transplantation, } \\
\text { ICSI = intracytoplasmic sperm injection, n.d. = not defined. }\end{array}$} \\
\hline \multicolumn{6}{|c|}{ †Further divided into subgroups according to autoantibodies, including ANA $(+)$ and LAC $(+)$} \\
\hline \multicolumn{6}{|c|}{$\begin{array}{l}\text { łFurther divided into } 2 \text { subgroups according to autoantibodies, including ANA(+)/APL(-) and } \\
\text { ANA(+)/APL(-) }\end{array}$} \\
\hline
\end{tabular}

\section{Intervention}

A variety of different protocols for GCs administration were used. The type of GCs were prednisone ${ }^{[32-35,}$ ${ }^{37]}$, methylprednisolone [36], prednisolone ${ }^{[31]}$, and dexamethasone ${ }^{[31]}$. Among these studies, most of them used only one particular GCs, except that Ando et al. prescribed 2 types of GCs, either dexamethasone or prednisolone, with no explanation of the basis for choosing which one to give ${ }^{[31]}$.

GCs were mostly used in low dose. However, the dose schedules and length of treatment were variable (table 2). Methylprednisolone was used in a dose of $8 \mathrm{mg} / \mathrm{d}$ by Ying et al. ${ }^{[36]}$. Prednisone was used in a

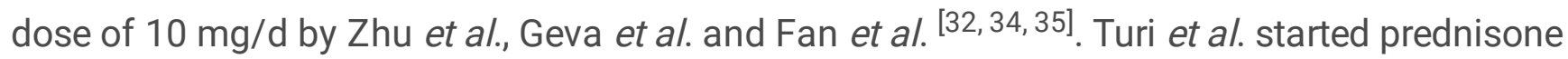
administration at the dose of $10 \mathrm{mg} / \mathrm{d}$ in the $1 \mathrm{st}$ week then gradually reduced the dosage until complete withdrawal ${ }^{[37]}$. Laskin et al. prescribed prednisone $0.8 \mathrm{mg} / \mathrm{kg} / \mathrm{d}$ for four weeks (maximum, $60 \mathrm{mg} / \mathrm{d}$ ) 
from confirmation of pregnancy by ultrasonography, followed by $0.5 \mathrm{mg} / \mathrm{kg} / \mathrm{d}$ (maximum $40 \mathrm{mg} / \mathrm{d}$ ) until delivery or fetal loss ${ }^{[33]}$. Ando et al. prescribed prednisolone $5 \mathrm{mg} / \mathrm{d}$ or dexamethasone $0.5 \mathrm{mg} / \mathrm{d}$ during the entire IVF cycle, and changed into prednisolone $5 \mathrm{mg} / \mathrm{d}$ after confirmation of pregnancy ${ }^{[31]}$. All studies use only oral regimens.

6 studies included involved ART. Among them, the assisted reproductive technique differed. Most assisted reproductive technology (ART) conducted was IVF-ET [31, 32, 34-36], except for one study used IUI ${ }^{[37]}, 1$ study did not mention whether ART was used ${ }^{[33]}$. In the 6 studies, treatment initation was related with ART cycle, GCs were provided consecutively during both luteal phase and follicular phase. GCs were administered either up to 3 months before IVF/ICSI cycle ${ }^{[34,36]}$ and induction of ovulation ${ }^{[35]}$, or 4 weeks before induction of ovulation ${ }^{[32]}$ or intrauterine insemination (IUI) ${ }^{[37]}$. Ando et al. ${ }^{[31]}$ administered GCs from IVF cycle. In 1 study without ART, GCs were provided from the confirmation of pregnancy [33].

Additional aspirin $100 \mathrm{mg} / \mathrm{d}^{[32-35]}, 81 \mathrm{mg} / \mathrm{d}^{[31]}$, or $50 \mathrm{mg} / \mathrm{d}^{[36]}$ was provided as adjuvant in most included studies except the one by Turi et al. ${ }^{[37]}$.

\section{Outcome}

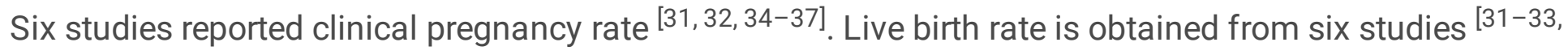
35-37]. In one study, the clinical observation stopped after the first trimester, so we classified those who did not miscarry by the end of the study as ongoing pregnancy ${ }^{[34]}$. With regard to miscarriage rate, 6 studies reported total miscarriage rate ${ }^{[31-33,35-37]}$. Geva et al. and Zhu et al. reported early miscarriage as well ${ }^{[32,34]}$. Other incidences in pregnancy were also recorded in some studies, including preterm birth, intrauterine death, neonatal death, ectopic pregnancy, hypertension (HTN) and gestational diabetes mellitus (GDM) [32,33].

\section{Effects of interventions}

\section{Clinical pregnancy rate per couple}

In six studies reported clinical pregnancy rate per couple, the result favors GCs use on improving clinical pregnancy rate (RR $2.19,95 \% \mathrm{Cl} 1.64$ to $2.92, P<0.00001,6$ cohort studies, 479 women, $P=39 \%$; Fig. 2 ).

We further conducted subgroup analysis for women with positive ANA and positive APL, and found that ANA-positive subgroup favors GC therapy (RR $2.54,95 \% \mathrm{Cl} 1.09$ to $5.89, P=0.03,3$ cohort studies, 213 women, $R=51 \%$ ) while APL-positive subgroup does not (RR 2.73, 95\% $\mathrm{Cl} 0.41$ to $18.27, P=0.30,2$ cohort studies, 176 women, $R=72 \%$; Fig. 3 ).

\section{Live birth rate per couple}

A total of 6 studies provided live birth rate as evaluating the effect of GCs administration, in which 2 studies supported GCs use and 4 studies showed no significant difference between GCs and control 
groups. Meta-analysis concluded that it favors peri-implantation GCs compared to no GCs (RR 1.92, 95\% $\mathrm{Cl} 1.17$ to $3.16, P=0.009,6$ cohort studies, 644 women, $P=64 \%$; Fig. 4 ).

We then conducted subgroup analysis based on autoantibodies. It showed that GCs could improve the live birth rate in women with positive ANA (RR 2.45, 95\% Cl 1.47 to 4.09, $P=0.0006,2$ cohort studies, 167 women, $R=0 \%$, Fig. 5). However, in women with positive APL, the result remained controversial (RR 2.22, $95 \% \mathrm{Cl} 0.66$ to $7.45, P=0.20,2$ cohort studies, 176 women, $P=40 \%$; Fig. 5).

To further understand the effect of GCs, we divided the studies into two subgroups according to initial time of treatment. 5 studies initiated GCs treatment before confirmation of pregnancy, 1 study after confirmation of pregnancy. The former favors GCs use (RR 2.30, $95 \% \mathrm{Cl} 1.58$ to $3.34, P<0.0001,5$ cohort studies, 442 women, $P=0 \%$; Fig. 6), while the latter did not (RR 1.16, 95\% Cl 0.93 to $1.45, P=0.20,1$ cohort study, 202 women; Fig. 6).

\section{Miscarriage rate per pregnancy}

The use of peri-implantation GCs on miscarriage rate per couple showed no statistical significance compared to no GCs (RR $0.75,95 \% \mathrm{Cl} 0.55$ to $1.02, P=0.06,6$ cohort studies, 340 women, $R=0 \%$; Fig. 7 ).

After dividing the studies according to initial treatment time, same result showed in both pre-pregnancy GCs group and post-pregnancy GCs group (GCs before pregnancy: RR $0.58,95 \% \mathrm{Cl} 0.31$ to $1.07, P=0.08$, 5 cohort studies, 138 women, $P=22 \%$; GCs after pregnancy: RR $0.80,95 \% \mathrm{Cl} 0.56$ to $1.13, P=0.20,1$ cohort study, 202 women; Fig. 8).

\section{Discussion}

There is a lack of consensus in the treatment of infertile women with unexplained positive autoantibody. For better understanding the effect of a commonly used drug, GCs, in this population, we conducted this systematic review and meta-analysis, and the major finding of our study is that GCs use has positive effect on improving clinical pregnancy rate and live birth rate in women with unexplained autoantibodies. Clinical pregnancy rate and live birth rate were improved only in ANA positive women without specific autoimmune disorder, but not in those with positive ACL. In addition, the effect on live birth rate is significant when GCs are administered before confirmation of pregnancy rather than after pregnancy.

4 RCTs and 2 cohort studies provided data on clinical pregnancy rate, in which 4 independent studies favored GCs use. Our systematic review and meta-analysis based on current studies confirmed the efficiency of GCs administration in improving clinical pregnancy rate in ANA but not APL positive women, which implies the different pathogenetic roles of diverse autoantibodies in establishing or maintening pregnancy. However, for subgroup with APL, we find data extracted from 2 studies are heterogenous and the sample size is small. Thus, examining whether GCs use can improve clinical pregnancy rate in APLpositive women needs further research. 
The analysis based on 5 studies providing live birth rate shows the same results that GCs use has a positive effect in increasing live birth rate only in ANA positive patients, but not in APL. These results indicate that patients with different autoantibodies may also have different immunologic characteristics and clinical outcomes, thus showed different responses to GCs.

Additional subgroup analysis was added to help determine the best time to start GCs therapy, and showed that preconception use of GCs improved live birth rate, while post-conception GCs administration did not. A meta-analysis conducted by Dan et al. showed that women experiencing unexplained recurrent miscarriage benefit significantly from prednisolone treatment after confirmation of pregnancy in terms of an increased live birth rate compared with placebo ${ }^{[38]}$. However, the population in the studies included in their meta-analysis was different from ours. They used high uterine natural killer cell density $(>5 \%)$, a test that is not popular in daily practice, as inclusion criteria, and known cause for recurrent miscarriage as exclusion criteria, but no mention of autoantibodies ${ }^{[39,40]}$. Therefore, difference in target population of the two studies may underlie the inconsistency in terms of the efficacy of GCs treatment. Furthermore, no effect in post-conception GCs treatment may also indicate risk in fetal exposure to exogenous GCs. A prospective controlled study collected and followed 311 pregnancies with systemic use of GCs in the first trimester. Higher rates of miscarriage $(11.5 \%$ versus $7.0 \%, P=0.013)$ and preterm birth $(22.7 \%$ versus $10.8 \%, P<0.001)$ were observed in GCs exposed group compared to the controls ${ }^{[41]}$. To date, prednisolone maintains a Category $\mathrm{D}$ rating with the Food and Drug Administration in the USA, indicating routine administration is not recommended. Therefore, further well-designed studies are needed to determine the best initial time and length of GCs therapy.

Miscarriage rate is not improved by GCs administration in neither 6 studies included nor our systematic review and meta-analysis. Same result is obtained from further subgroup analysis concerning the initiation time of GCs treatment. The miscarriage rate in subgroup "GCs administration before pregnancy" in our study is $9.4 \%$, which is comparable to $13.5 \%$ reported by Anderson et al. ${ }^{[42]}$. Only 1 study is included in post-conception GCs administration subgroup, and the miscarriage rate is lower than control group without statistical significance. As discussed before, early fetal exposure to exogenous GCs may cause risk in miscarriage. Therefore, identifying the optimal indication for GCs use after confirmation of pregnancy warrant further well-designed study with large sample size.

Our study has several limitations that have to be considered when it comes to interpretation of the data. First, as mentioned before, our meta-analysis included only seven studies due to lack of related studies. However, because the question is so important and sample size is small in each study, and couldn't give clinicians effective guidance, so it is necessary to have meta-analysis and systematic review to help us get more comprehensive information. Although several borderline effects needs to be confirmed by larger sample size, our study still provides preliminary information that is important for further studies. Second, the dosage, type and the therapeutic course of GCs among included trials were of a great discrepancy. Using placebo or not is also inconsistent between studies. Third, the type and dose of adjuvant therapy varies in studies included, and the effect of these therapies, such as oral aspirin, on changing pregnancy 
outcome are not clear ${ }^{[43-45]}$. The effect of GCs use in women with unexplained positive autoantibody needs further investigations of high quality to confirm. To gain better understanding of this therapy, welldesigned prospective, randomized, controlled clinical trials must be proposed.

Based on our finding, the recommendations for future study design are listed below. First, the type of GCs should not be long acting GCs including dexamethasone or betamethasone, for they can pass through placenta and cause adverse effects such as fetal malformation. Second, the dose is not necessarily high, $10 \mathrm{mg} / \mathrm{d}$ prednisone/prednisolone or less is possibly enough to have positive effect. Third, the therapeutic course covering 1-3 months before confirmation of pregnancy or controlled ovarian hyperstimulation is recommended, although the effect of post-conception GCs therapy initiation needs further understanding. Adjuvant therapy such as anticoagulants can be added, but should be comparable in both control and GCs groups. Forth, patients should be divided into different subgroups according to their type of autoantibodies.

\section{Conclusion}

our systemic review and meta-analysis report improvement in clinical pregnancy rate and live birth rate of GCs use in women with unexplained positive autoantibody. Further investigation is required to ascertain its efficacy.

\section{Declarations}

Ethical Approval and Consent to participate:

Not needed in meta-analysis.

Consent for publication:

Yes.

\section{Availability of supporting data:}

All data generated or analysed during this study are included in this published article.

\section{Competing interests:}

The authors declare that they have no competing interests.

\section{Funding:}

This work is not funded by any organization.

\section{Acknowledgements:}


The authors wish to thank all researchers of the included studies who provided additional data.

\section{Authors' information:}

Nothing to report.

\section{Authors' contributions:}

Ting Li, Yilin Yuan, Rong Mu and Qun Lu conceived and designed the study. Ting Li and Yilin Yuan performed the literature search, data extraction, and assessed the risk of bias and overall quality of evidence. Rong Mu resolved disagreement between Ting Li and Yilin Yuan. Ting Li, Yilin Yuan and Huixin Liu performed and interpreted the data analysis. Ting Li and Yilin Yuan drafted the manuscript. Rong Mu revised the manuscript. All authors read and approved the final manuscript.

\section{References}

1. Haas, D.M., T.J. Hathaway, and P.S. Ramsey, Progestogen for preventing miscarriage in women with recurrent miscarriage of unclear etiology. Cochrane Database Syst Rev, 2018. 10: p. Cd003511.

2. Ramos-lbeas, P., et al., Senescence and Apoptosis During in vitro Embryo Development in a Bovine Model. Front Cell Dev Biol, 2020. 8: p. 619902.

3. Graham, M.C., K.M. Hoeger, and W.R. Phipps, Initial IVF-ET experience with assisted hatching performed 3 days after retrieval followed by day 5 embryo transfer. Fertil Steril, 2000. 74(4): p. 66871.

4. Wang, N.F., et al., Immunologic Abnormalities, Treatments, and Recurrent Pregnancy Loss: What Is Real and What Is Not? Clinical obstetrics and gynecology, 2016. 59(3): p. 509-523.

5. Vander Borght, M. and C. Wyns, Fertility and infertility: Definition and epidemiology. Clin Biochem, 2018. 62: p. 2-10.

6. Norgard, B.M., et al., Decreased chance of a live born child in women with rheumatoid arthritis after assisted reproduction treatment: a nationwide cohort study. Ann Rheum Dis, 2019. 78(3): p. 328-334.

7. Schreiber, K., et al., Antiphospholipid syndrome. Nature Reviews Disease Primers, 2018. 4: p. 17103.

8. Shetty, S. and K. Ghosh, Anti-phospholipid antibodies and other immunological causes of recurrent foetal loss-a review of literature of various therapeutic protocols. American journal of reproductive immunology (New York, N.Y. : 1989), 2009. 62(1): p. 9-24.

9. Moher, D., et al., Preferred reporting items for systematic reviews and meta-analyses: the PRISMA statement. PLoS Med, 2009. 6(7): p. e1000097.

10. Geva, E., et al., Prednisone and aspirin improve pregnancy rate in patients with reproductive failure and autoimmune antibodies: a prospective study. American journal of reproductive immunology (New York, N.Y. : 1989), 2000. 43(1): p. 36-40.

11. Ordi, J., et al., Fetal loss treatment in patients with antiphospholipid antibodies. Annals of the rheumatic diseases, 1989. 48(10): p. 798-802. 
12. Vaquero, E., et al., Pregnancy outcome in recurrent spontaneous abortion associated with antiphospholipid antibodies: a comparative study of intravenous immunoglobulin versus prednisone plus low-dose aspirin. American journal of reproductive immunology (New York, N.Y. : 1989), 2001. 45(3): p. 174-179.

13. Ye, S.-L., et al., Efficacy of Different Treatment Regimens for Antiphospholipid Syndrome-related Recurrent Spontaneous Abortion. Chinese medical journal, 2017. 130(12): p. 1395-1399.

14. Hasegawa, l., et al., Effectiveness of prednisolone/aspirin therapy for recurrent aborters with antiphospholipid antibody. Human reproduction (Oxford, England), 1992. 7(2): p. 203-207.

15. Hasegawa, l., et al., Prednisolone plus low-dose aspirin improves the implantation rate in women with autoimmune conditions who are undergoing in vitro fertilization. Fertility and sterility, 1998. 70(6): p. 1044-1048.

16. Moradan, S. and R. Ghorbani, Dexamethasone in unexplained infertility. Saudi medical journal, 2009. 30(8): p. 1034-1036.

17. Siristatidis, C., et al., Addition of prednisolone and heparin in patients with failed IVF/ICSI cycles: a preliminary report of a clinical trial. Human fertility (Cambridge, England), 2013. 16(3): p. 207-210.

18. $\mathrm{Ou}, \mathrm{H}$. and Q. Yu, [Effects of combination therapy with aspirin, prednisone, and Elevit in patients with unexplained recurrent early pregnancy loss]. Zhonghua yi xue za zhi, 2017. 97(41): p. 3250-3254.

19. Siristatidis, C., et al., Administration of prednisolone and low molecular weight heparin in patients with repeated implantation failures: a cohort study. Gynecological endocrinology : the official journal of the International Society of Gynecological Endocrinology, 2018. 34(2): p. 136-139.

20. Moffitt, D., et al., Low-dose glucocorticoids after in vitro fertilization and embryo transfer have no significant effect on pregnancy rate. Fertility and sterility, 1995. 63(3): p. 571-577.

21. Ubaldi, F., et al., Low dose prednisolone administration in routine ICSI patients does not improve pregnancy and implantation rates. Human reproduction (Oxford, England), 2002. 17(6): p. 15441547.

22. Duvan, C.I., et al., Does addition of low-dose aspirin and/or steroid as a standard treatment in nonselected intracytoplasmic sperm injection cycles improve in vitro fertilization success? A randomized, prospective, placebo-controlled study. Journal of assisted reproduction and genetics, 2006. 23(1): p. 15-21.

23. Fawzy, M., et al., Treatment options and pregnancy outcome in women with idiopathic recurrent miscarriage: a randomized placebo-controlled study. Archives of gynecology and obstetrics, 2008. 278(1): p. 33-38.

24. Kilic, S., et al., The effect of anti-thyroid antibodies on endometrial volume, embryo grade and IVF outcome. Gynecol Endocrinol, 2008. 24(11): p. 649-55.

25. Revelli, A., et al., Low-dose acety/salicylic acid plus prednisolone as an adjuvant treatment in IVF: a prospective, randomized study. Fertil Steril, 2008. 90(5): p. 1685-91.

26. Tang, A.-W., et al., A feasibility trial of screening women with idiopathic recurrent miscarriage for high uterine natural killer cell density and randomizing to prednisolone or placebo when pregnant. Human 
reproduction (Oxford, England), 2013. 28(7): p. 1743-1752.

27. Fawzy, M. and A.-A.A. El-Refaeey, Does combined prednisolone and low molecular weight heparin have a role in unexplained implantation failure? Archives of gynecology and obstetrics, 2014. 289(3): p. 677-680.

28. Gomaa, M.F., et al., Combined oral prednisolone and heparin versus heparin: the effect on peripheral NK cells and clinical outcome in patients with unexplained recurrent miscarriage. A double-blind placebo randomized controlled trial. Archives of gynecology and obstetrics, 2014. 290(4): p. 757-762.

29. Litwicka, K., et al., In women with thyroid autoimmunity, does low-dose prednisolone administration, compared with no adjuvant therapy, improve in vitro fertilization clinical results? The journal of obstetrics and gynaecology research, 2015. 41(5): p. 722-728.

30. Stern, C., et al., A randomized, double-blind, placebo-controlled trial of heparin and aspirin for women with in vitro fertilization implantation failure and antiphospholipid or antinuclear antibodies. Fertility and Sterility, 2003. 80(2): p. 376-383.

31. Ando, T., et al., Successful glucocorticoid treatment for patients with abnormal autoimmunity on in vitro fertilization and embryo transfer. J Assist Reprod Genet, 1996. 13(10): p. 776-81.

32. Geva, E., et al., Prevention of early pregnancy loss in autoantibody seropositive women. Lancet (London, England), 1998. 351(9095): p. 34-35.

33. Laskin, C.A., et al., Prednisone and aspirin in women with autoantibodies and unexplained recurrent fetal loss. The New England journal of medicine, 1997. 337(3): p. 148-153.

34. Zhu, Q., et al., A retrospective study on IVF/ICSI outcome in patients with anti-nuclear antibodies: the effects of prednisone plus low-dose aspirin adjuvant treatment. Reproductive biology and endocrinology : RB\&E, 2013. 11: p. 98.

35. Fan, J., Y. Zhong, and C. Chen, Combined treatment of prednisone and aspirin, starting before ovulation induction, may improve reproductive outcomes in ANA-positive patients. American journal of reproductive immunology (New York, N.Y. : 1989), 2016. 76(5): p. 391-395.

36. Ying, Y., et al., A retrospective study on IVF outcome in patients with anticardiolipin antibody: effects of methylprednisolone plus low-dose aspirin adjuvant treatment. Journal of reproductive immunology, 2012. 94(2): p. 196-201.

37. Turi, A., et al., Preconception steroid treatment in infertile women with antithyroid autoimmunity undergoing ovarian stimulation and intrauterine insemination: a double-blind, randomized, prospective cohort study. Clin Ther, 2010. 32(14): p. 2415-21.

38. Dan, S., et al., Effect of Prednisolone Administration on Patients with Unexplained Recurrent Miscarriage and in Routine Intracytoplasmic Sperm Injection: A Meta-Analysis. American journal of reproductive immunology (New York, N.Y. : 1989), 2015. 74(1): p. 89-97.

39. Tang, A.W., et al., Prednisolone Trial: Study protocol for a randomised controlled trial of prednisolone for women with idiopathic recurrent miscarriage and raised levels of uterine natural killer (uNK) cells in the endometrium. Trials,10,1(2009-11-10), 2009. 10(1): p. 102-102. 
40. Ai-Wei, T., et al., A feasibility trial of screening women with idiopathic recurrent miscarriage for high uterine natural killer cell density and randomizing to prednisolone or placebo when pregnant. Human Reproduction, 2013. 28(7): p. 1743-1752.

41. Gur, C., et al., Pregnancy outcome after first trimester exposure to corticosteroids: a prospective controlled study. Reproductive Toxicology, 2004. 18(1): p. 93-101.

42. Andersen, A.-M.N., et al., Maternal age and fetal loss: population based register linkage study. BMJ : British Medical Journal, 2000. 320(7251): p. 1708-1712.

43. Rai, R., et al., Randomised controlled trial of aspirin and aspirin plus heparin in pregnant women with recurrent miscarriage associated with phospholipid antibodies (or antiphospholipid antibodies). Bmj British Medical Journal, 1997. 314(7076): p. 253-257.

44. Dendrinos, S., E. Sakkas, and E. Makrakis, Low-molecular-weight heparin versus intravenous immunoglobulin for recurrent abortion associated with antiphospholipid antibody syndrome. International Journal of Gynecology \& Obstetrics, 2009. 104(3): p. 223-225.

45. Schisterman, E.F., et al., Preconception low-dose aspirin and pregnancy outcomes: results from the EAGeR randomised trial. Lancet, 2014. 384(9937): p. 29-36.

\section{Table}

Table 2 is not available with this version.

\section{Figures}




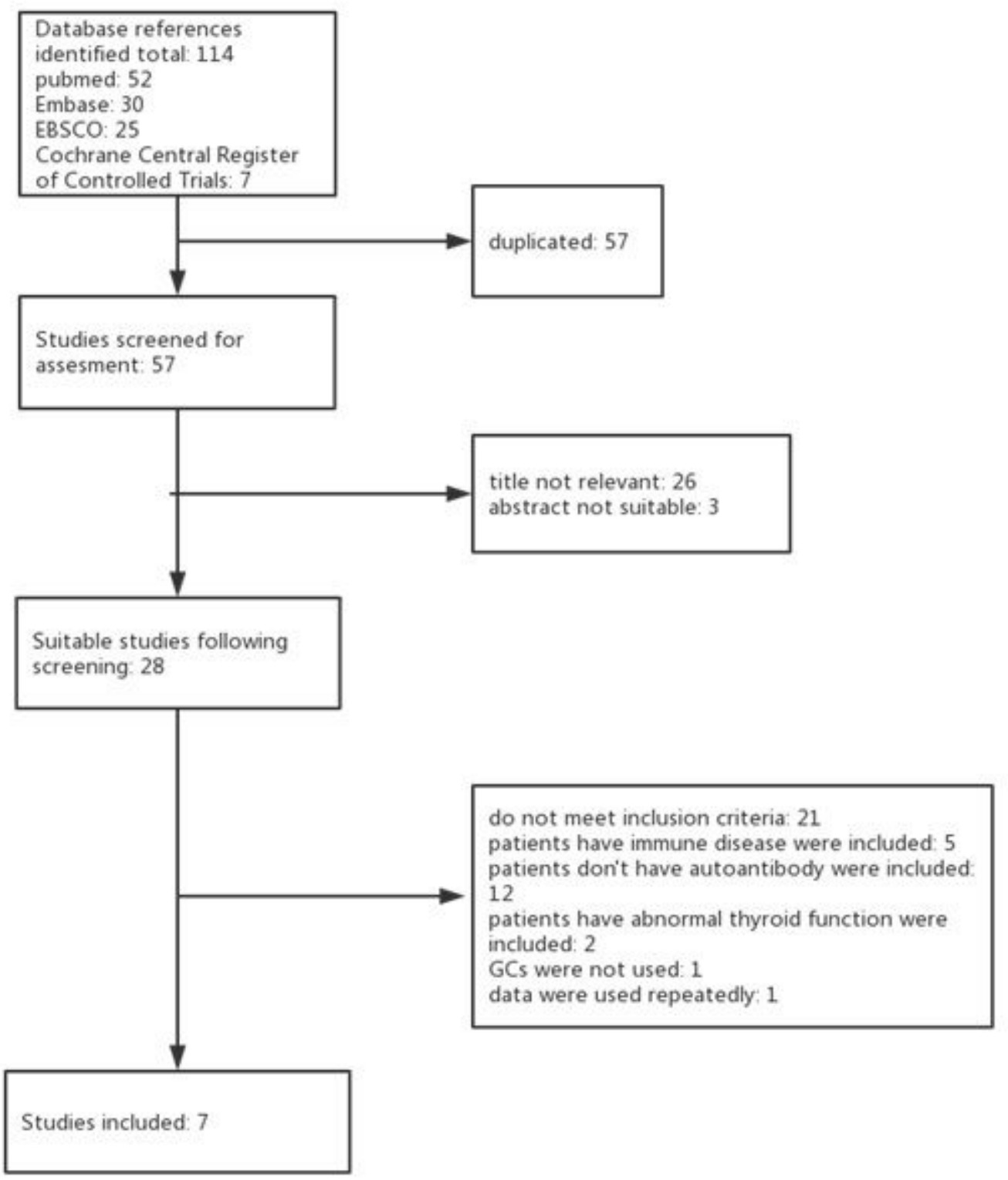

Figure 1

The process of finding studies.

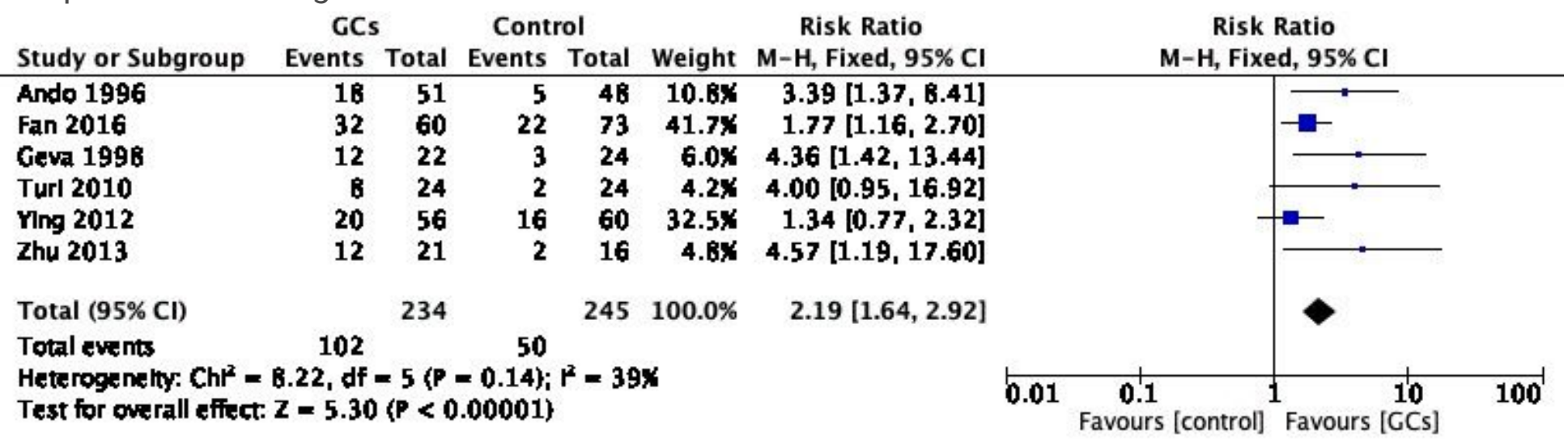


Figure 2

Forrest plot for comparison: GCs versus no GCs/placebo, outcome: I.I Clinical pregnancy rate per couple. 6 studies reported clinical pregnancy rate per couple. The result favors GCs use on improving clinical pregnancy rate (RR $2.19,95 \% \mathrm{Cl} 1.64$ to $2.92, \mathrm{P}<0.00001,6$ cohort studies, 479 women, $12=39 \%$ ).

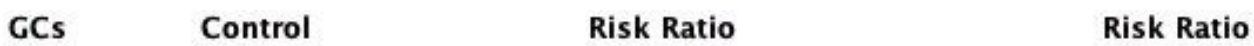

Heterogenelty: $\mathrm{Tau}^{2}=1.44 ; \mathrm{Ch}^{2}=3.59, \mathrm{df}=1(\mathrm{P}=0.06) ; \mathrm{r}^{2}=72 \mathrm{~K}$

Test for overall effect: $Z=1.04(P=0.30)$

Test for subgroup difierences: $\mathrm{Ch}^{2}=0.01$, df $=1(\mathrm{P}=0.94), \mathrm{I}^{2}=0 \mathrm{x}$ M-H, Random, 95\% CI

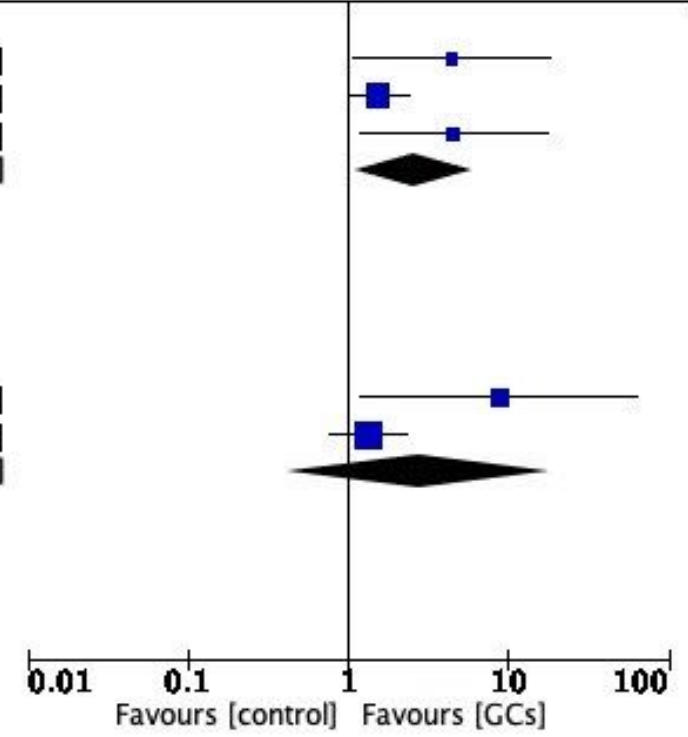

Figure 3

Forrest plot comparison: GCs versus no GCs/placebo, outcome: I.II Clinical pregnancy rate per couple in subgroups by autoantibody. ANA-positive subgroup favors GC therapy while APL-positive subgroup does not (ANA: RR 2.54, 95\% Cl 1.09 to 5.89, P = 0.03 , 3 cohort studies, 213 women, I2 = 51\%; APL: RR 2.73, $95 \% \mathrm{Cl} 0.41$ to $18.27, \mathrm{P}=0.30,2$ cohort studies, 176 women, $\mathrm{I} 2=72 \%$ ).

\section{GCs Control Risk Ratio}

Study or Subgroup Events Total Events Total Weight $\mathrm{M}-\mathrm{H}, \mathrm{Random}, 95 \% \mathrm{Cl}$

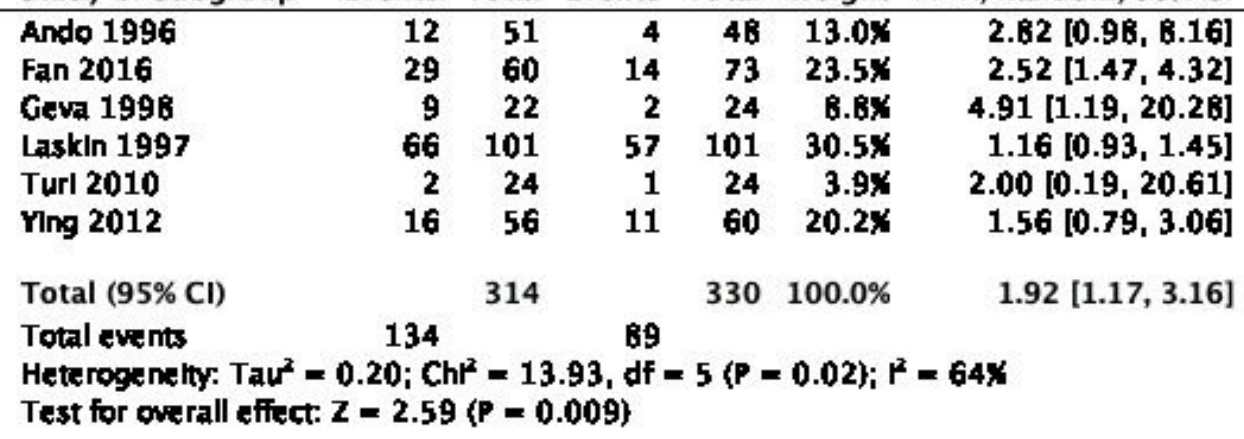

Figure 4

Forrest plot for comparison: GCs versus no GCs/placebo, outcome: II.I Live birth rate per couple. A total of 7 studies provided live birth rate as evaluating the effect of GCs administration. Meta-analysis concluded
Risk Ratio M-H, Random, 95\% CI

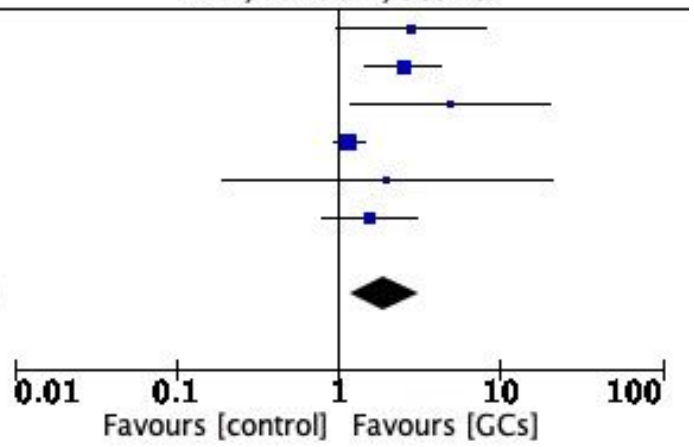


that it favors peri-implantation GCs compared to no GCs (RR 1.92, 95\% Cl 1.17 to 3.16, $\mathrm{P}=0.009,6$ cohort studies, 644 women, 12 = 64\%).

GCs Control Risk Ratio

Study or Subgroup Events Total Events Total Weight $\mathrm{M}-\mathrm{H}$, Random, $95 \% \mathrm{Cl}$

$\begin{array}{lrrrrrr}\text { Ando 1996 } & 3 & 15 & 2 & 19 & 9.6 \% & 1.90[0.36,9.95] \\ \text { Fan 2016 } & 29 & 60 & 14 & 73 & 90.4 \% & 2.52[1.47,4.32] \\ \text { Subtotal }(95 \% \mathrm{Cl}) & & 75 & & 92 & 100.0 \% & 2.45[1.47,4.09]\end{array}$

Total events $\quad 32 \quad 16$

Heterogenelty: $\mathrm{Tat}^{2}=0.00 ; \mathrm{Chr}^{2}=0.10, \mathrm{df}=1(\mathrm{P}=0.75) ; \mathrm{r}^{2}=0 \mathrm{X}$

Test for overall effect: $Z=3.43(P=0.0006)$

1.6.2 APL

$\begin{array}{lrrrrrr}\text { Ando } 1996 & 7 & 32 & 1 & 28 & 25.9 \% & 6.13[0.80,46.78] \\ \text { Ylng } 2012 & 16 & 56 & 11 & 60 & 74.1 \times & 1.56[0.79,3.06] \\ \text { Subtotal }(95 \% \mathrm{Cl}) & & 88 & & 88 & 100.0 \% & 2.22[0.66,7.45]\end{array}$

Total events $23 \quad 12$

Heterogenelty: $\mathrm{Tau}^{2}=0.40 ; \mathrm{ChP}^{2}=1.66, \mathrm{df}=1(\mathrm{P}=0.20) ; \mathrm{P}^{2}=40 \mathrm{x}$

Test for overall effect: $Z=1.29(\mathrm{P}=0.20)$

Test for subgroup differences: $\mathrm{Ch}^{2}=0.02, \mathrm{df}=1(\mathrm{P}=0 . \mathrm{BB}), \mathrm{P}^{2}=0 \mathrm{x}$

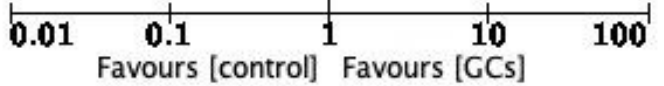

Figure 5

Forrest plot for comparison: GCs versus no GCs/placebo, outcome: II.II Live birth rate per couple in subgroups by autoantibody. GCs could improve the live birth rate in women with positive ANA (RR 2.45, $95 \% \mathrm{Cl} 1.47$ to $4.09, \mathrm{P}=0.0006,2$ cohort studies, 167 women, $12=0 \%$ ). However, in women with positive $\mathrm{APL}$, the result remained controversial (RR $2.22,95 \% \mathrm{Cl} 0.66$ to $7.45, \mathrm{P}=0.20,2$ cohort studies, 176 women, $12=40 \%$ )

GCs Control Risk Ratio

Risk Ratio

Study or Subgroup Events Total Events Total Weight M-H, Random, $95 \% \mathrm{Cl}$

\begin{tabular}{lrlrrrr}
\hline 1.7.1 glucocorticoids before pregnancy & & & & \\
Ando 1996 & 12 & 51 & 4 & 48 & $12.3 \%$ & $2.82[0.98,1.16]$ \\
Fan 2016 & 29 & 60 & 14 & 73 & $47.8 \%$ & $2.52[1.47,4.32]$ \\
Geva 1998 & 9 & 22 & 2 & 24 & $6.9 \%$ & $4.91[1.19,20.28]$ \\
Turl 2010 & 2 & 24 & 1 & 24 & $2.6 \%$ & $2.00[0.19,20.61]$ \\
Ylng 2012 & 16 & 56 & 11 & 60 & $30.4 \%$ & $1.56[0.79,3.06]$ \\
Subtotal (95\% Cl) & & 213 & & 229 & $100.0 \%$ & $2.30[1.58,3.34]$ \\
Total events & 68 & & 32 & & &
\end{tabular}

Heterogeneity: $\mathrm{Tau}^{2}=0.00 ; \mathrm{Ch}^{2}=2.66, \mathrm{df}=4(\mathrm{P}=0.62) ; \mathrm{I}^{2}=0 \mathrm{x}$

Test for overall effect: $Z=4.3 B(P<0.0001)$

1.7.2 glucocorticoids after pregnancy

$\begin{array}{lllllll}\text { Laskln } 1997 & 66 & 101 & 57 & 101 & 100.0 \% & 1.16[0.93,1.45] \\ \text { Subtotal }(95 \% \mathrm{Cl}) & & 101 & & 101 & 100.0 \% & 1.16[0.93,1.45]\end{array}$

Total events $\quad 66 \quad 57$

Heterogenelty: Not applicable

Test for overall effect: $Z=1.29(P=0.20)$

Test for subgroup differences: $\mathrm{Ch}^{2}=9.59, \mathrm{df}=1(\mathrm{P}=0.002), \mathrm{I}^{2}=89.6 \mathrm{X}$

M-H, Random, 95\% CI

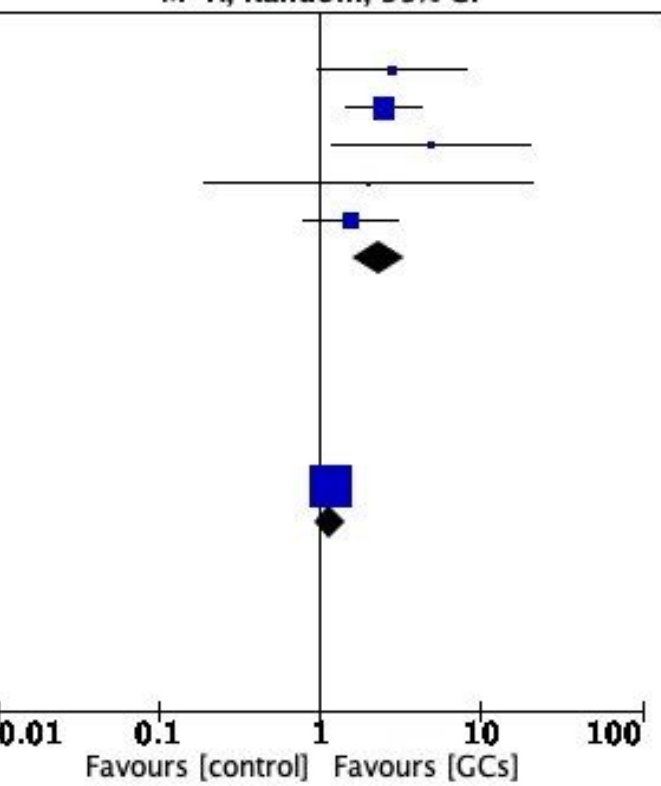

Figure 6 
Forrest plot for comparison: GCs versus no GCs/placebo, outcome: II.III Live birth rate per couple in subgroups by time of treatment. 5 studies initiated GCs treatment before confirmation of pregnancy, 1 study after confirmation of pregnancy. The former favors GCs use (RR 2.30, 95\% Cl 1.58 to 3.34, P < $0.0001,5$ cohort studies, 442 women, $12=0 \%$, while the latter did not (RR $1.16,95 \% \mathrm{Cl} 0.93$ to $1.45, \mathrm{P}=$ $0.20,1$ cohort study, 202 women)

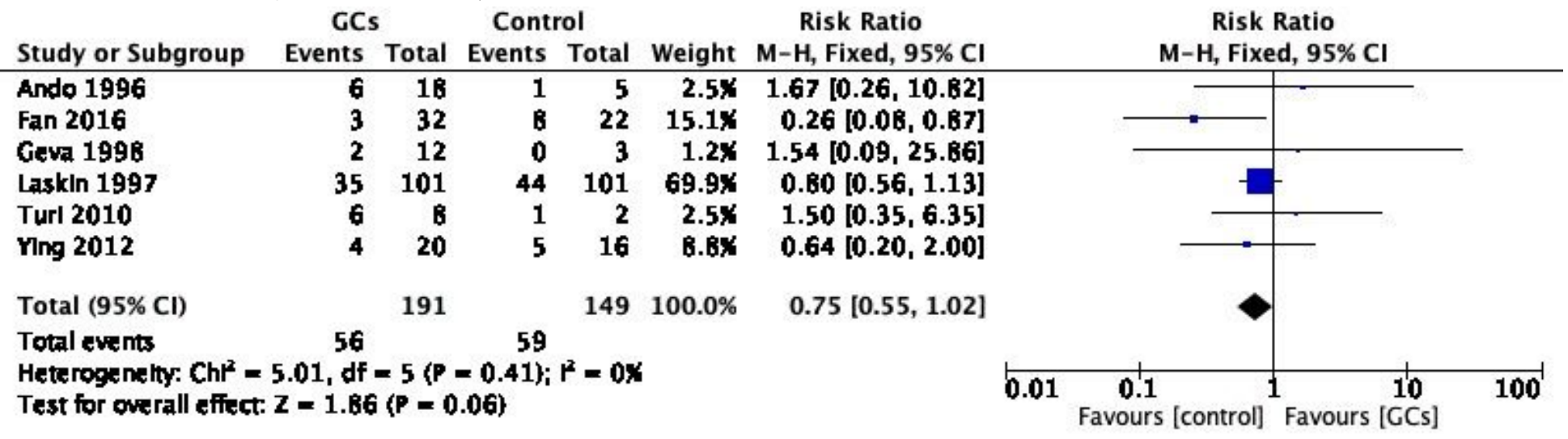

Figure 7

Forrest plot for comparison: GCs versus no GCs/placebo, outcome: Ill.I Miscarriage rate per clinical pregnancy. The use of peri-implantation GCs on miscarriage rate per couple showed no statistical significance compared to no GCs (RR $0.75,95 \% \mathrm{Cl} 0.55$ to $1.02, \mathrm{P}=0.06,6$ cohort studies, 340 women, 12 $=0 \%$.

$$
\text { GCs Control Risk Ratio }
$$

Study or Subgroup Events Total Events Total Weight M-H, Fixed, $95 \% \mathrm{CI}$

\begin{tabular}{llllrrr}
\hline 1.9 .1 glucocorticoids before pregnancy & & & & \\
Ando 1996 & 6 & 18 & 1 & 5 & $7.9 \%$ & $1.67[0.26,10.82]$ \\
Fan 2016 & 3 & 32 & $B$ & 22 & $47.9 \%$ & $0.26[0.08,0.87]$ \\
Geva 1998 & 1 & 12 & 1 & 3 & $8.1 \%$ & $0.25[0.02,2.94]$ \\
Turl 2010 & 6 & $B$ & 1 & 2 & $8.1 \%$ & $1.50[0.35,6.35]$ \\
Ying 2012 & 4 & 20 & 5 & 16 & $28.1 \%$ & $0.64[0.20,2.00]$ \\
Subtotal $(95 \% \mathrm{Cl})$ & & 90 & & 48 & $100.0 \%$ & $0.58[0.31,1.07]$
\end{tabular}

Total events $\quad 20 \quad 16$

Heterogenelty: $\mathrm{Ch}^{2}=5.10, \mathrm{df}=4(\mathrm{P}=0.2 \mathrm{~B}) ; \mathrm{P}^{2}=22 \mathrm{Y}$

Test for overall effect: $Z=1.75$ (P $=0.08)$

1.9.2 glucocorticoids after pregnancy

$\begin{array}{lllllll}\text { Laskin } 1997 & 35 & 101 & 44 & 101 & 100.0 \% & 0.80[0.56,1.13] \\ \text { Subtotal }(95 \% \mathrm{Cl}) & & 101 & & 101 & 100.0 \% & 0.80[0.56,1.13] \\ \text { Total events } & 35 & & 44 & & & \end{array}$

Heterogenelty: Not applicable

Test for overall effect: $Z=1.29(P=0.20)$

Test for subgroup differences: $\mathrm{Ch}^{2}=0.80$, df $=1(\mathrm{P}=0.37), \mathrm{I}^{2}=0 \mathrm{x}$

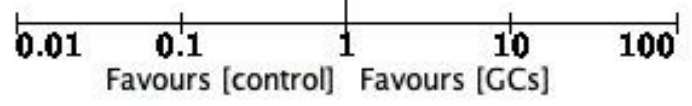

Figure 8

Forrest plot for comparison: GCs versus no GCs/placebo, outcome: III.II Miscarriage rate per clnical pregnancy in subgroups by time of treatment. 6 studies were divided into 2 subgroups according to initial 
treatment time, same result showed for both pre-pregnancy GCs use and post-pregnancy GCs use (GCs before pregnancy: RR $0.58,95 \% \mathrm{Cl} 0.31$ to $1.07, \mathrm{P}=0.08,5$ cohort studies, 138 women, $\mathrm{I} 2=22 \%$; GCs after pregnancy: RR $0.80,95 \% \mathrm{Cl} 0.56$ to $1.13, \mathrm{P}=0.20,1$ cohort study, 202 women).

\section{Supplementary Files}

This is a list of supplementary files associated with this preprint. Click to download.

- SupplmentryTables.docx 